\title{
Clinical Significance of Cough Peak Flow and Its Non-Contact Measurement via Cough Sounds: A Narrative Review
}

\author{
Yasutaka Umayahara ${ }^{1, *(1)}, \mathrm{Zu} \mathrm{Soh}^{2} \oplus$, Kiyokazu Sekikawa ${ }^{3}$, Toshihiro Kawae ${ }^{4}$, Akira Otsuka ${ }^{1}$ \\ and Toshio Tsuji ${ }^{2, *}$ \\ 1 Department of Rehabilitation, Faculty of Health Sciences, Hiroshima Cosmopolitan University, \\ 3-2-1 Otsukahigashi, Asaminami-ku, Hiroshima-shi, Hiroshima 731-3166, Japan; otsuka-1949@hcu.ac.jp \\ 2 Department of Electrical, Systems, and Control Engineering, Faculty of Advanced Science and Engineering, \\ Hiroshima University, 1-4-1 Kagamiyama, Higashi-Hiroshima, Hiroshima 739-8527, Japan; \\ sozu@bsys.hiroshima-u.ac.jp \\ 3 Division of Physical Analysis and Therapeutic Sciences, Institute of Biomedical and Health Sciences, \\ Hiroshima University, 1-2-3 Kasumi, Minami-ku, Hiroshima-shi, Hiroshima 734-8553, Japan; \\ sekikawa@hiroshima-u.ac.jp \\ 4 Department of Physical Therapy, Faculty of Makuhari Human Care, Tohto University, 1-3 Nakase, \\ Mihama-ku, Chiba-shi, Chiba 261-8501, Japan; toshihiro@hiroshima-u.ac.jp \\ * Correspondence: umayahara-creha@umin.ac.jp (Y.U.); tsuji@bsys.hiroshima-u.ac.jp (T.T.); \\ Tel.: +81-82-849-6883 (Y.U.); Fax: +81-82-849-6884 (Y.U.)
}

Received: 22 February 2020; Accepted: 14 April 2020; Published: 17 April 2020

\begin{abstract}
Coughing is the primary defence mechanism against foreign bodies in the central airways and can quantitatively be assessed by cough peak flow (CPF). We conducted a narrative review of the literature on $\mathrm{CPF}$, which is most commonly used for evaluating cough strength. This review regards the method for measurement of $\mathrm{CPF}$, the cough-related factors influencing $\mathrm{CPF}$, the clinical significance of $\mathrm{CPF}$ evaluation, and a novel cough strength prediction method using cough sounds. Furthermore, this review presents various cutoff thresholds that predict extubation failure in patients on mechanical ventilation, acute respiratory failure, and aspiration risk. The published clinical evidence of CPF demonstrates reasonable diagnostic accuracy, predictive power, and validity, although additional studies on the non-contact measurement of CPF via cough sounds with better-quality methodologies are required.
\end{abstract}

Keywords: cough; cough peak flow; cough strength; cough sounds; mobile device

\section{Introduction}

Previous data have shown that $60 \%$ of community-acquired pneumonia and $87 \%$ of hospital-acquired pneumonia patients are diagnosed with aspiration pneumonia [1]. Thus, detecting the risk of aspiration pneumonia for early treatment is very important.

Evaluating cough strength is as effective as evaluating the swallowing function [2,3] for preventing aspiration or aspiration pneumonia [4,5]. It has been suggested that researchers should focus on approaches to improve coughing dysfunction, rather than developing new antibiotics, in order to decrease mortality due to aspiration pneumonia in the elderly [6].

Cough peak flow (CPF) has been employed as a measure for evaluating cough strength and the risk of cough dysfunction [7]. Many guidelines for the respiratory management of patients with neuromuscular disease have been published by various academic societies and recommend CPF measurement. The British Thoracic Society guidelines for the respiratory management of children 
with neuromuscular weakness recommended that CPF should be used as part of the assessment of effective secretion clearance in children with neuromuscular disease over 12 years of age [8].

This review explains the measurement and evaluation method of CPF as a reflection of cough strength, its related factors, and its clinical significance. Furthermore, a non-contact measurement method for cough strength using cough sounds is introduced in this review.

\section{Cough Mechanism and Related Factors Influencing CPF}

European Respiratory Society guidelines show that coughing is a three-phase expulsive motor act constituted by an inspiratory effort (inspiratory phase), followed by a forced expiratory effort against a closed glottis (compressive phase) and then by opening of the glottis and rapid expiratory airflow (expulsive phase) $[9,10]$. In addition, there is also the concept of a four-phase cough, including the irritation phase, in which a cough reflex begins with the stimulation of an irritant receptor [11]. Figure 1 shows the four phases of a normal cough.

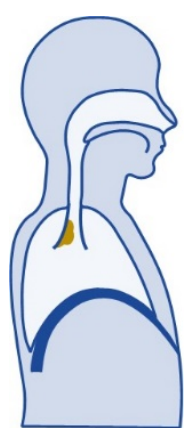

(a)

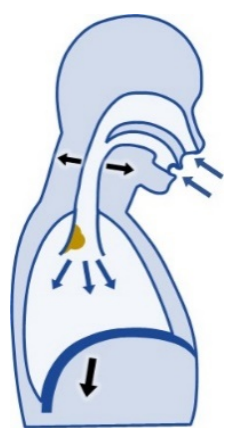

(b)

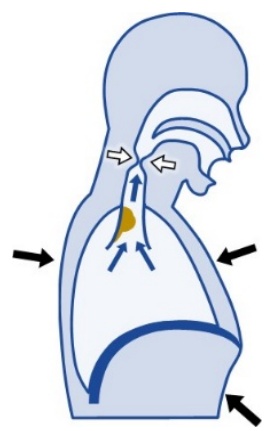

(c)

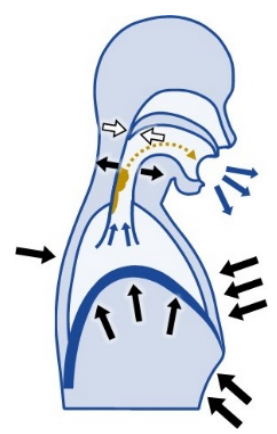

(d)

Figure 1. Four phases of a cough [11]. (a) Irritation phase. (b) Inspiration phase. (c) Compression phase. (d) Expulsion phase. The blue arrows represent air flow. The black arrows represent movements of each part. The white arrows represent airway closure. The brown parts represent mucus and foreign material. The brown dots represent the movement of mucus and foreign material from the lower airway to the upper airway. Modified from Cherniack RM, Naimark A: Respiration in health and disease, Philadelphia, 1972, WB Saunders.

The inhalation cough challenge permits measurement of the sensitivity of the cough reflex during the irritation phase (Figure 1a) [9]. In general, inhalation cough challenge testing uses capsaicin [12], citric, and tartaric acid $[13,14]$. A recent study developed a testing device that can easily and simultaneously measure the CPF and the time interval from the inhalation of an ultrasound-nebulized solution of tartaric acid to the cough reflex to facilitate the evaluation of cough strength and cough reflex sensitivity [3]. This study also reported that both the CPF and the time until the cough reflex was significantly lower in patients with dysphagia than in normal subjects [3]; however, further investigations are needed to clarify the relevance of these differences.

In the inspiration phase (Figure 1b), the cough centre generates a reflex stimulation of the respiratory muscles to induce deep inspiration. Thus, the volume inspired before coughing (operating volume) and the function of the inspiratory muscles are essential for coughing [15]. The functional residual capacity is a strong and significant predictor of the operating volume (adjusted $R^{2}=0.45$, $p<0.01$ ) [16]. In normal adults, the operating volume is approximately $3.4 \mathrm{~L}$ [16]. In addition, the operating volume is an important determinant of the CPF $[16,17]$, and the CPF has a significant positive association with the maximal inspiratory pressure, which is a marker of inspiratory muscle weakness in patients with cervical spinal cord injuries [18] and in males over 60 years old [19].

During the compression phase (Figure 1c), cough reflex nerve impulses cause glottal closure and forceful contraction of the expiratory muscles. This compression phase normally lasts approximately $0.2 \mathrm{~s}$. Furthermore, intrathoracic pressures during voluntary cough range from 58 to $214 \mathrm{cmH}_{2} \mathrm{O}$ 
and are associated with the CPF [20]. To increase intrathoracic pressure for coughing, glottal closure and expiratory muscle strength are important. The maximal expiratory pressure (MEP), an index of expiratory muscle strength, is also associated with the CPF [18].

In the expulsion phase (Figure 1d), the glottis opens together with continued contraction of the expiratory muscles, causing an expulsive flow of air from the lungs. Cough flow and dynamic airway compression cause very large shear forces on the airway walls. As a result, mucus and foreign material can be expelled from the lower airways to the upper airway.

As described above, $\mathrm{CPF}$ is a measure closely related to the four cough phases. Moreover, previous studies have shown that CPF is related to age, vital capacity (VC) [18,19], height, weight [21], physical activity, sex [22], and hand grip strength [19].

\section{Clinical Significance of CPF Evaluation}

\subsection{Conventional CPF Measurement Methods}

Figure 2 shows examples of conventional CPF measurement devices. Various spirometers [3,23-26] and peak flow meters [24,26-30] are used for CPF measurement. Moreover, various flow sensors, such as a pneumotachograph $[21,23-25,31]$ that measures respiratory flow using differential pressure sensors, a constant temperature hot-wire flow sensor (Figure 2a) [26,32] and an ultrasonic sensor [33], are used in spirometers. In particular, the peak flow meter that can measure the flow rate using a spring-loaded piston is most commonly used because of its small size and ease of use, enabling patients to measure CPF by themselves (Figure 2b). However, Kulnik [34] raised a problem with the accuracy of various peak flow meters compared with the that of the pneumotachograph and called attention to the following points. It is important to recognize that, depending on the measurement instrument, absolute values of CPF reported in literature may not be directly comparable. Similarly, peak flow meters should be used with caution when measuring CPF in clinical practice, particularly with respect to directing patient management, as this can be considered an off-label use of these instruments [34]. On the other hand, the reliability and validity of some peak flow meters were verified. Thus, it is necessary to understand the characteristics of various CPF measurement devices and select the appropriate device depending on the user's purpose.
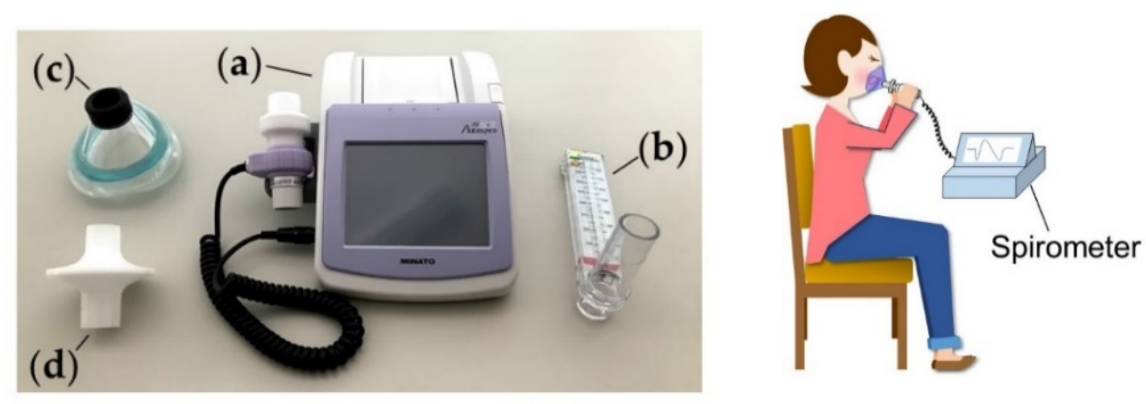

(e)

Figure 2. Cough peak flow (CPF) measurement devices and posture. (a) Spirometer. (b) Peak flow meter. (c) Face mask. (d) Infection prevention filter. (e) Conventional CPF measurement method.

There are two types of accessories for CPF measurement: a mouthpiece and a face mask. These accessories are attached to the peak flow meter or the flow sensor of the spirometer. Figure $2 \mathrm{c}$ shows the face mask. Clinically, the face mask is used instead of the mouthpiece for CPF measurement because patients with neuromuscular diseases have difficulty holding the mouthpiece with their mouth while they cough, and cough air leaks from the corner of the mouth. The use of different mask sizes may influence the airflow being measured because of the difference in capacity between various masks. A previous study reported that there were no statistically significant differences in CPF among various masks of different sizes [21]. However, there are no other reports on whether the use of different 
mask sizes for different participants can influence the cough airflow being measured. Thus, more methodologically rigorous studies are needed to definitively identify the effect of the mask size on $\mathrm{CPF}$. Figure $2 \mathrm{~d}$ shows an infection prevention filter. Although there are quite a few papers that do not describe the use of infection prevention filters in the measurement method, the filter should be used.

The purpose and technique of CPF measurement should be explained to all participants before the measurement; moreover, how to perform the measurement [21] should be demonstrated. Participants are instructed to close the glottis after each insufflation and to coughing [27,28]. After one or two trial attempts, participants are instructed to make a maximal effort and are closely watched to ensure no air leakage from the gap between the mask and face. When using a mouthpiece instead of the mask, a nose clip must be worn. To assess CPF, subjects perform a maximal cough effort after an as deep an inspiration as possible.

\subsection{Neuromuscular Disease}

In a previous study of patients over 11 years of age with Duchenne muscular dystrophy (DMD) published in 1997, Bach [35] showed that CPF could be used to assess the risk of DMD patients developing acute respiratory failure because no patients with a CPF above $270 \mathrm{~L} / \mathrm{min}$ developed acute respiratory distress. In addition, a recent study involving thirty-four patients with amyotrophic lateral sclerosis [36] reported that the CPF decline rate reflects the progression of bulbar and respiratory dysfunction and is an independent prognostic factor for survival as, patients exhibiting a CPF decline rate over $25 \%$ had a shorter overall survival $(p<0.0001)$. Moreover, in adults and probably also children above 12 years of age, a CPF above $160 \mathrm{~L} / \mathrm{min}$ is required to effectively clear secretions and maintain airway patency [8] because patients with an assisted CPF under $160 \mathrm{~L} / \mathrm{min}$ cannot be successfully extubated or decannulated [27]. Even in patients with diseases other than neuromuscular diseases such as pneumonia, asthma, and chronic obstructive pulmonary disease exacerbations, CPF is commonly used to evaluate the cough strength to predict re-intubation in intensive care units (ICUs). Previous studies have found that the optimal cutoff value for CPF was $35 \mathrm{~L} / \mathrm{min}$ as reported by Beuret et al. [37], $60 \mathrm{~L} / \mathrm{min}$ as reported by Smina et al. [7], and $62.4 \mathrm{~L} / \mathrm{min}$ as reported by Duan et al. [38].

Manually mechanically assisted coughing that augments cough flow is often employed to reduce the health risk. Forced exhalation can be augmented by pushing on the upper abdomen or chest wall in synchrony with the patient's own cough effort [39]. Glossopharyngeal breathing (GPB) and air stacking can increase the lung volume and cough flow [40]. The maximum insufflation capacity (MIC) is the maximum volume of air stacked within the patient's lungs beyond the spontaneous vital capacity [8], which is one of the determinants of CPF. The application of positive pressure with a self-inflating bag and mask, an intermittent positive pressure breathing device, and a mechanical ventilator are effective techniques to increase the MIC [39]. In addition, mechanical insufflation-exsufflation (MIE) is used as a mechanical technique to assist in coughing. MIE and an oximeter are prescribed when the patient's maximum assisted CPF declines below $300 \mathrm{~L} / \mathrm{min}[41,42]$. Recent studies have reported that MIE exsufflation (cough) flow (MIE-EF) correlates with upper airway patency $[43,44]$ and that a successful transition from invasive to noninvasive respiratory management requires an MIE-EF value of at least 150 to $200 \mathrm{~L} / \mathrm{min}$ [44].

To obtain an effective peak flow to expel airway secretions, we should appropriately select cough assist techniques according to the patient's condition. Generally, cough assist techniques should be used to achieve a baseline CPF above $160 \mathrm{~L} / \mathrm{min}[8,39]$. However, several guidelines recommend that cough assist techniques should be used in patients with neuromuscular disease when their CPF is below $270 \mathrm{~L} / \mathrm{min}[8,39]$ because DMD patients are at risk of developing acute respiratory failure when their (assisted) CPF is below $270 \mathrm{~L} / \mathrm{min}$ [35].

\subsection{Risk Management in Aspiration Pneumonitis}

The swallowing function and coughing are important to defend against aspiration pneumonia. A previous study of 68 healthy subjects aged 20-91 years published in 2014 reported that swallowing 
function worsened with increasing age, with a significant decline after 80 years, and that a swallow risk index correlated with increasing age [45]. Ageing is associated with both respiratory muscle strength and CPF [22]. In a previous study of 55 dysphagic patients published in 2012, Bianchi [2] showed that a CPF lower than $242 \mathrm{~L} / \mathrm{min}$ predicted the development of pulmonary complications with a sensitivity of $77 \%$ and a specificity of $83 \%$; the positive and negative predictive values were $65 \%$ and $90 \%$, respectively. Moreover, the latest research reported that CPF can be used as a predictor of aspiration risk in elderly individuals with community-acquired pneumonia [46]. Therefore, $\mathrm{CPF}$ measurement should be widely used as a screening test for preventing aspiration pneumonia in the elderly.

\section{Non-Contact Measurement of CPF via Cough Sounds}

\subsection{CPF Estimation Model Using Cough Sounds}

CPF was measured using various devices (Figure 2). However, some medical facilities do not provide these devices [25], and some studies have used a semiquantitative cough strength assessment method [47,48]. Moreover, the complex setup of the device, including firm attachment of the facemask and infection control filter to the patient, imposes a burden on both patients and caregivers. In addition, the measured CPF can vary depending on the type of facemask and filter. Furthermore, the mask, which should be firmly attached to the patient's face to prevent air leakage, makes it difficult for the subject to cough naturally and voluntarily.

These problems could be solved by the use of cough sounds. Several previous studies proposed methods to monitor cough frequency using a microphone [49-51], and measurements of cough frequency using cough sound were introduced by the European Respiratory Society guidelines in 2007 [9]. However, no other studies attempted to design cough sound measurements of CPF. Reportedly, the relationship between air flow and the amplitude of breath sounds is linear at high flow rates [52,53]. It has also been reported that the sound amplitude during inspiration is proportional to the square of the air flow velocity at the mouth [54]. Moreover, recent studies have shown that cough sounds are associated with cough flow (Figure 3a) $[55,56]$, and a method for estimating cough strength via cough sounds has been developed using a model represented by an exponential equation [56], given as follows:

$$
C P F=\alpha\{\exp (\beta \cdot C P S L)-1\},
$$

where $\alpha$ and $\beta$ are constants, and CPSL is the cough peak sound pressure level. Figure $3 \mathrm{~b}$ shows the relationship between CPF and CPF predicted via cough sounds (CPS) calculated using Equation (1), confirming a significant positive correlation $(r=0.920 ; p<0.001)$ in young healthy participants. In a previous study published in 2001, Smith $H$ [57] showed that the cough sound pressure level is $94.30 \pm 1.48 \mathrm{~dB}$ in patients with stroke and $106.11 \pm 0.34 \mathrm{~dB}$ in nonstroke elderly patients screened for the absence of pulmonary illness. Furthermore, the loudness of the cough sound may be an indicator of the aspiration severity. Although the cough sound measurement methods used by Smith $\mathrm{H}$ et al. and Umayahara et al. [56] differ, the cough sound range reported by Smith $\mathrm{H}$ et al. is consistent with the loud region of the cough sound-measured value reported by Umayahara et al.

Figure 4 shows examples of simultaneously measured cough flow and cough sounds. A previous study reported that the absolute error between CPFs and CPSs when the microphone distance from the participant's mouth was within $30 \mathrm{~cm}$ was significantly lower than that when the distance exceeded $30 \mathrm{~cm}$ [56]. Although cough flow and cough sounds were measured through different methods, both responded to the initiation of the participant's cough. The figure also indicates that the cough sound appears faster than the cough flow. According to the European Respiratory Society guidelines on the assessment of coughing [9], the cough sound is defined as having three phases: the explosive phase, the intermediate phase, and the voiced phase. The cough sound pattern shown in Figure $4 \mathrm{~b}$ is a two-phase cough sound without a voiced phase. 


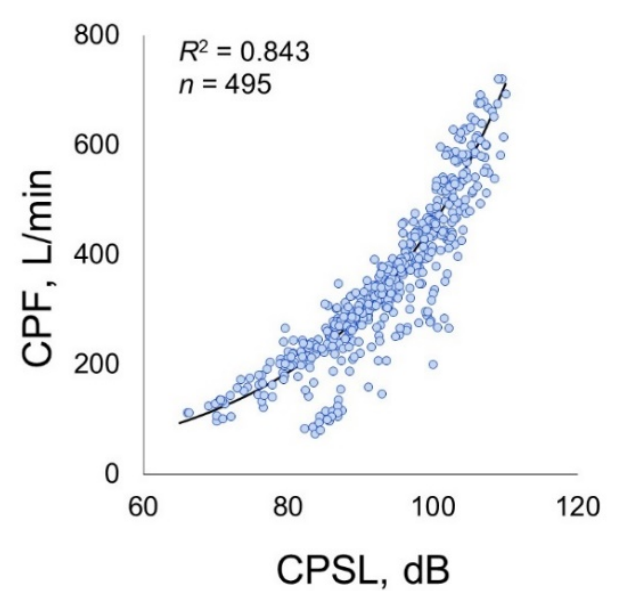

(a)

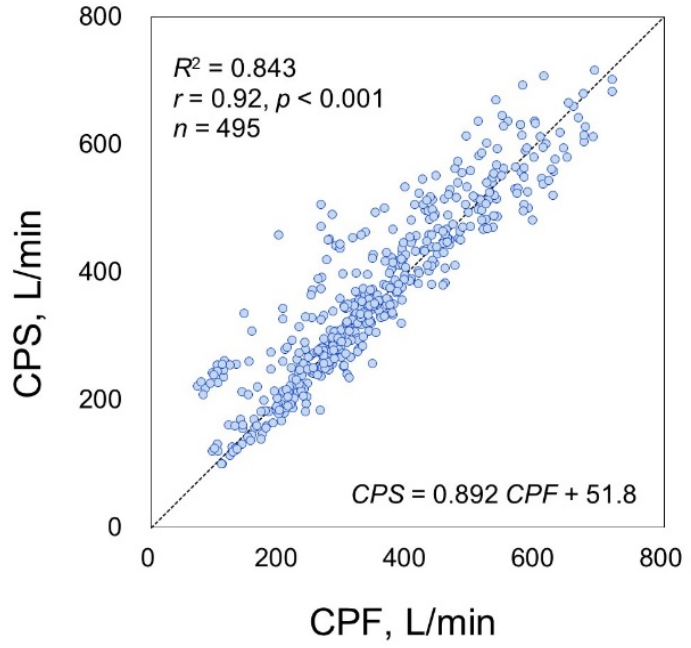

(b)

Figure 3. Accuracy of the CPF estimation model using cough sounds. (a) Relationship of CPF and CPSL. CPF, cough peak flow; CPSL, cough peak sound pressure level. (b) Relationship of CPS and CPF. CPS, cough peak flow predicted via cough sounds. Modified from Umayahara Y: Estimation of cough peak flow using cough sounds, Sensors, 2018 [56].

\section{(a)}

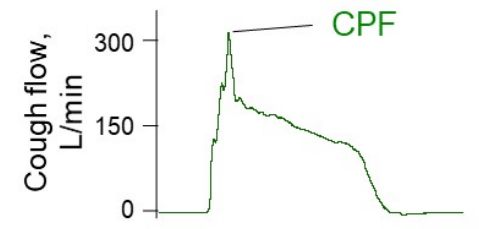

(b)
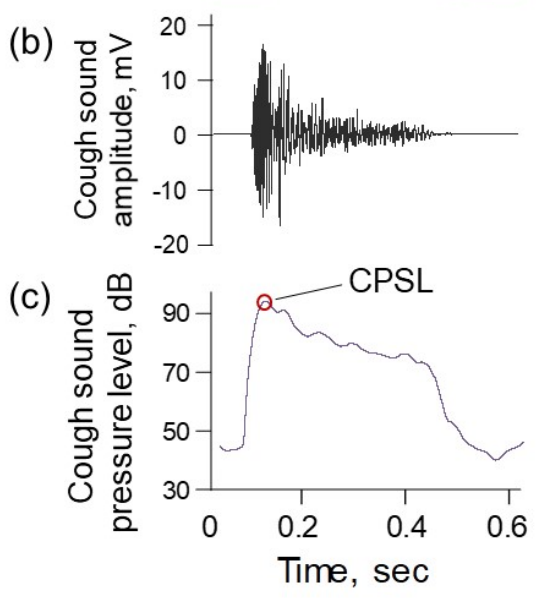

Figure 4. Examples of cough flow and cough sound in a young healthy participant [56]. (a) Cough flow. The green line represents the cough flow measured by a flow sensor (Mobile aeromonitor AE-100i, Minato Medical Science Co., Ltd., Osaka, Japan). (b) Cough sound amplitude. The grey line represents the cough sound signals measured by the microphone (AT9903, Audio-Technica Corporation, Tokyo, Japan). The digitized cough sound signals were band-pass filtered between 140 to $2000 \mathrm{~Hz}$ to minimize artefacts. (c) Cough sound pressure level. The solid purple line represents the moving average with a time window of $20 \mathrm{~ms}$. The cough flow and sound measurement was performed with the participants in a sitting position. The participants wore a face mask with an attached flow sensor. An electret condenser microphone was installed $30 \mathrm{~cm}$ from the point where the face mask contacted the face and was attached to the flow sensor. 
Moreover, the age term improves the CPF estimation accuracy [58]. The sound quality may change with age, but its effect on CPF estimation can be compensated for by adding a proportional age coefficient, as follows:

$$
C P F=\left(\alpha_{0}+\alpha_{1} \cdot \operatorname{age}\right)\{\exp (\beta \cdot C P S L)-1\},
$$

where $\alpha_{0}, \alpha_{1}$ and $\beta$ are constants, and age is the participant's age. The CPF estimated by Equation (2) is called CPS to distinguish it from CPF. Although height [56], body weight and BMI can also affect the estimation accuracy [58], these physical characteristics reportedly have minimal effects on the CPF estimation accuracy [58].

\subsection{Non-Contact CPF Measurement Device}

Figure 5 shows a non-contact cough strength measurement evaluation method based on cough sounds. Cough sounds can easily be measured using various microphones [56]. The device incorporates the CPF estimation model for mobile devices that enables cough sound recording and immediate CPF estimation and provides a user interface allowing CPS history management [58]. This device can facilitate a screening test to detect decreased cough strength in home medical care; however, the reliability and validity of CPS have yet to be fully determined. Previous studies have not fully considered the effects of disease and airway mucous because the participants were healthy volunteers $[55,56,58]$. Furthermore, the cough sounds were measured in a quiet ordinary room. A major problem with this method was the influence of sounds reflected from the walls and/or sound attenuation. Therefore, it is necessary to verify the reliability and validity of CPS and improve the accuracy of CPS estimation in patients for further clinical application.

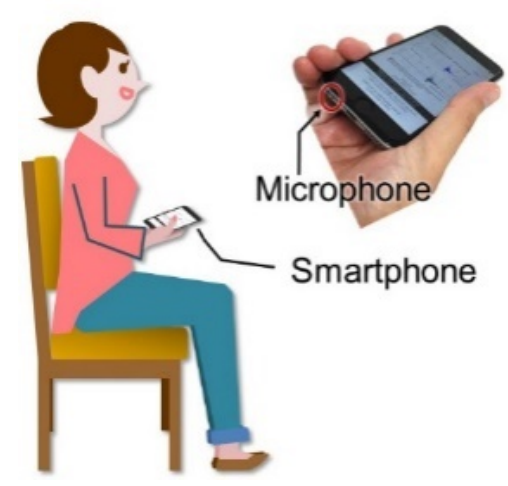

Figure 5. Non-contact cough strength evaluation method. The smartphone (iPhone 6 A1586; Apple, Inc., Cupertino, CA, USA) was held in the left hand while the participant bent the elbow to 90 degrees and the shoulder to 0 degrees and then rotated the arm internally to 45 degrees.

\subsection{Evaluation of Cough Strength Using a Smartphone in the Elderly and in a Patient with Spinal Muscular Atrophy}

Figure 6 shows examples of elderly participants' cough sound patterns measured using a smartphone [58]. In the case shown in Figure 6a, although the respiratory function test showed vital capacity (VC) and forced expiratory volume in one second/forced vital capacity ( $\left.\mathrm{FEV}_{1} / \mathrm{FVC}\right)$ values exceeding the reference value, the cough strength values, such as CPS and CPF, were below the reference value of $270 \mathrm{~L} / \mathrm{min}$. In the case in Figure $6 \mathrm{~b}$, both respiratory function and cough strength exceeded the reference value. In these cases, the CPS was almost the same value as the CPF and could be used to estimate cough strength. The evaluation of cough strength using a smartphone demonstrated a median relative error of $13.55 \%$ in elderly participants and $6.19 \%$ in young participants [58]. 


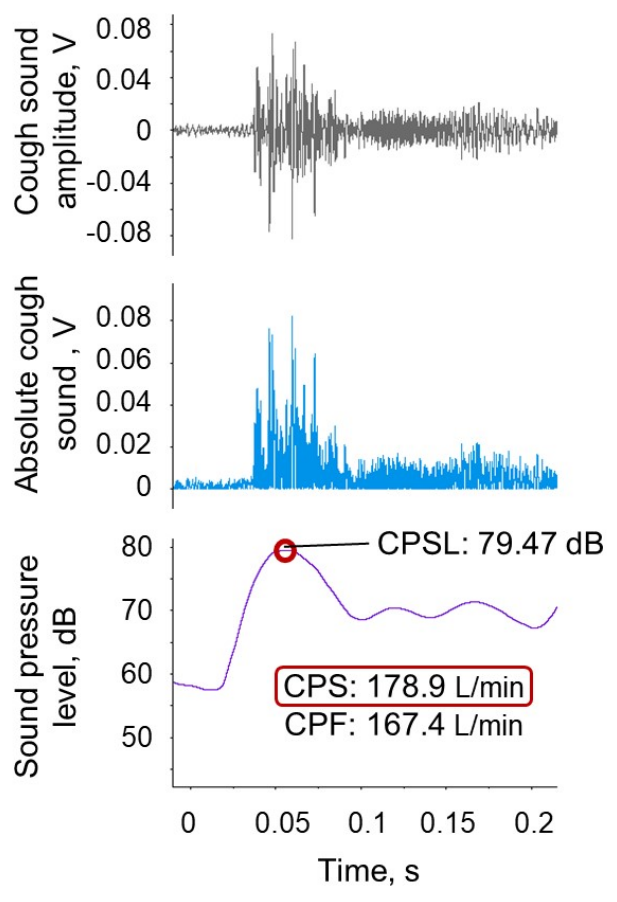

(a)
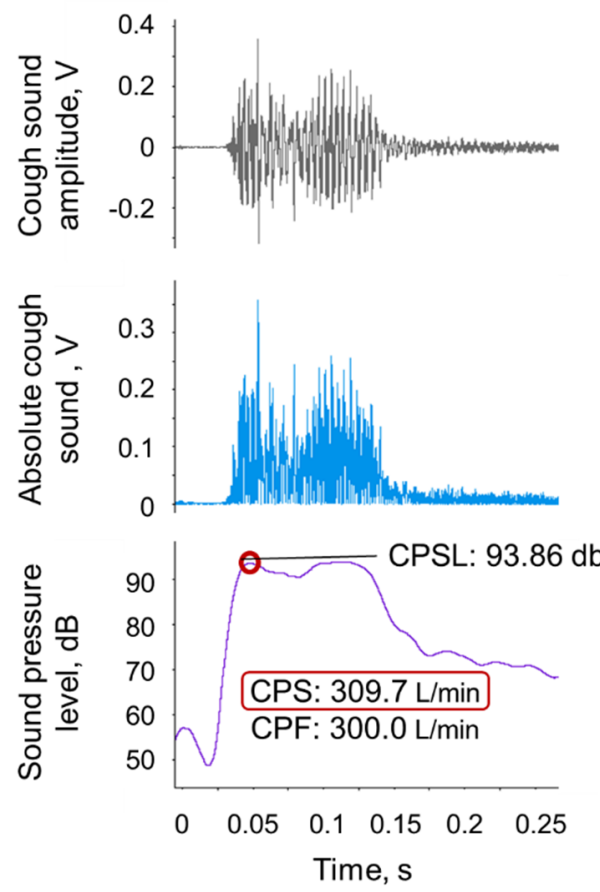

(b)

Figure 6. Examples of cough sound patterns in elderly participants [58]. The grey line represents the measured cough sound signal. The solid light blue line represents the bandpass-filtered and rectified sound signal. The solid purple line represents the moving average with a time window of $20 \mathrm{~ms}$. The red circle represents the maximum point of the moving average. (a) Example of a 77-year-old woman with a measured CPF below the reference value of $270 \mathrm{~L} / \mathrm{min}$. The respiratory function test showed slightly low values of $\%$ Vital Capacity $(\mathrm{VC})=83.5 \%$ and one second/forced vital capacity $(\mathrm{FEV} 1 / \mathrm{FVC})=83.0 \%$. (b) Example of a 70-year-old man with a measured CPF above the reference value of $270 \mathrm{~L} / \mathrm{min}$. The respiratory function test showed normal values of $\% \mathrm{VC}=91.6 \%$ and $\mathrm{FEV} 1 / \mathrm{FVC}=94.9 \%$.

Figure 7 shows changes in unassisted and volume-assisted cough sounds in a 20-year-old man with spinal muscular atrophy. The low cough strength of this patient warranted access to mechanically assisted coughing, such as mechanical insufflation-exsufflation, during intercurrent respiratory infections. In this case, we attempted evaluate the cough strength using a smartphone (iPhone 6) with reference to a method reported in a previous study [58]. With the assisted cough, the cough sound amplitude could be clearly detected from the measured sound; however, the unassisted cough yielded a very weak cough sound, which could result in difficulty detecting the cough sound amplitude against noise.

The previous study did not fully consider cough sound frequencies, although breathing sounds can be influenced by sound frequencies [21,22]. The estimation accuracy could thus be further improved by considering the frequency domain. In addition, because the non-contact CPF measurement method was aimed at the daily evaluation of coughing ability and risk screening, it is implicitly assumed to be applicable to healthy or close to healthy users; however, application in users with a disease or airway mucous is also expected. 


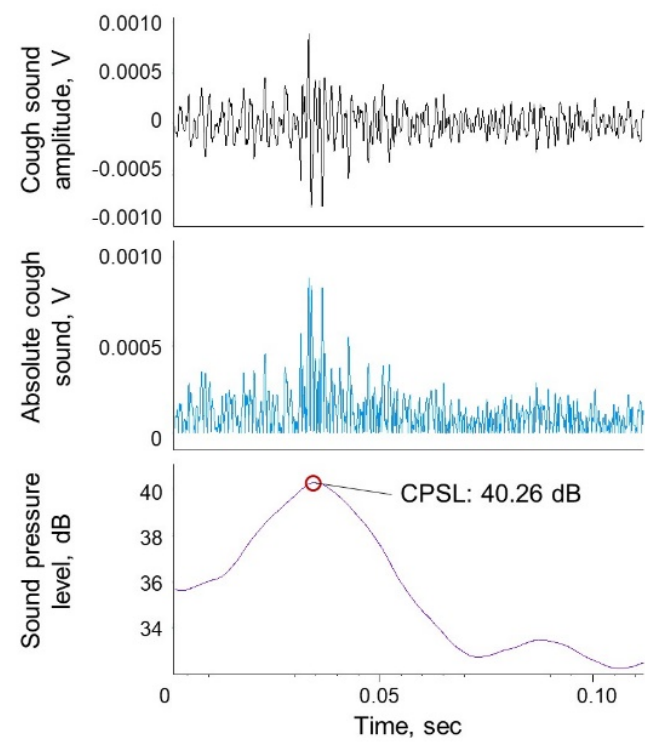

(a)

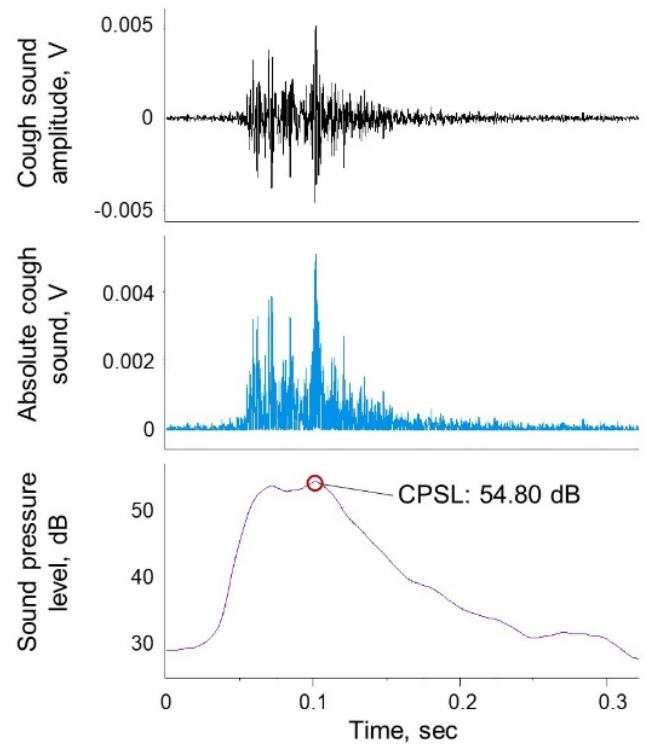

(b)

Figure 7. Changes in unassisted and volume-assisted cough sounds in a 20-year-old man with spinal muscular atrophy. The patient used nasal noninvasive positive-pressure ventilation at night. His VC and maximum insufflation capacity (MIC) values were $450 \mathrm{~mL}$ and $1050 \mathrm{~mL}$, respectively. The volume-assisted CPF was defined as CPF generated from maximum insufflation by air stacking. The volume-assisted CPS was defined similarly. The unassisted and volume-assisted CPF values were measured by an Access peak flow meter (Philips Respironics, Bend, OR, USA). The grey line represents the measured cough sound signal. The solid light blue line represents the bandpass-filtered and rectified sound signal. The solid purple line represents the moving average with a time window of 20 ms. The red circle represents the maximum point of the moving average. (a) Unassisted cough sound. The unassisted CPF and CPS values were $80 \mathrm{~L} / \mathrm{min}$ and $77.8 \mathrm{~L} / \mathrm{min}$, respectively. (b) Volume-assisted cough sound. The assisted CPF and CPS values were $150 \mathrm{~L} / \mathrm{min}$ and $135.6 \mathrm{~L} / \mathrm{min}$, respectively.

\section{Conclusions}

CPF was used as a predictor of extubation failure in patients on mechanical ventilation, acute respiratory failure, and aspiration. It should be noted that there are various measurement devices and accessories, such as face masks and/or filters, that affect CPF. Human factors, such as the patient's posture during measurement, are also unignorable. Therefore, these effects on measured CPF values need to be definitively investigated. To improve the accuracy and reliability of CPF measurements, including the CPF measurement method using cough sounds, a more detailed examination is required.

\section{Patents}

There is a patent resulting from the work reported in this manuscript. Y.U., Z.S., A.O. and T.T. have written patents for cough strength evaluation devices, systems, methods and programs.

Author Contributions: Writing—original draft preparation, Y.U. and A.O.; writing—review and editing, Y.U., K.S., Z.S., T.K., A.O., and T.T.; visualization, Y.U. and Z.S.; supervision, A.O. and T.T.; project administration, Y.U., K.S., T.K., Z.S. and T.T.; funding acquisition, Y.U. All authors have read and agreed to the published version of the manuscript.

Funding: This research was supported by JSPS KAKENHI, grant number 16K16475.

Conflicts of Interest: The authors declare no conflict of interest. 


\section{References}

1. Teramoto, S.; Fukuchi, Y.; Sasaki, H.; Sato, K.; Sekizawa, K.; Matsuse, T.; Japanese Study Group on Aspiration Pulmonary Disease. High incidence of aspiration pneumonia in community- and hospital-acquired pneumonia in hospitalized patients: A multicenter, prospective study in Japan. J. Am. Geriatr. Soc. 2008, 56, 577-579. [CrossRef] [PubMed]

2. Bianchi, C.; Baiardi, P.; Khirani, S.; Cantarella, G. Cough peak flow as a predictor of pulmonary morbidity in patients with dysphagia. Am. J. Phys. Med. Rehabil. 2012, 91, 783-788. [CrossRef] [PubMed]

3. Fujiwara, K.; Kawamoto, K.; Shimizu, Y.; Fukuhara, T.; Koyama, S.; Kataoka, H.; Kitano, H.; Takeuchi, H. A novel reflex cough testing device. BMC Pulm. Med. 2017, 17, 19. [CrossRef] [PubMed]

4. Chang, A.B. The physiology of cough. Paediatr. Respir. Rev. 2006, 7, 2-8. [CrossRef] [PubMed]

5. Schmit, K.M.; Coeytaux, R.R.; Goode, A.P.; McCrory, D.C.; Yancy, W.S., Jr.; Kemper, A.R.; Hasselblad, V.; Heidenfelder, B.L.; Sanders, G.D. Evaluating cough assessment tools: A systematic review. Chest 2013, 144, 1819-1826. [CrossRef] [PubMed]

6. Ebihara, S.; Sekiya, H.; Miyagi, M.; Ebihara, T.; Okazaki, T. Dysphagia, dystussia, and aspiration pneumonia in elderly people. J. Thorac. Dis. 2016, 8, 632-639. [CrossRef]

7. Smina, M.; Salam, A.; Khamiees, M.; Gada, P.; Amoateng-Adjepong, Y.; Manthous, C.A. Cough peak flows and extubation outcomes. Chest 2003, 124, 262-268. [CrossRef]

8. Hull, J.; Aniapravan, R.; Chan, E.; Chatwin, M.; Forton, J.; Gallagher, J.; Gibson, N.; Gordon, J.; Hughes, I.; McCulloch, R.; et al. British Thoracic Society guideline for respiratory management of children with neuromuscular weakness. Thorax 2012, 67 (Suppl. 1), i1-i40. [CrossRef]

9. Morice, A.H.; Fontana, G.A.; Belvisi, M.G.; Birring, S.S.; Chung, K.F.; Dicpinigaitis, P.V.; Kastelik, J.A.; McGarvey, L.P.; Smith, J.A.; Tatar, M.; et al. ERS guidelines on the assessment of cough. Eur. Respir. J. 2007, 29, 1256-1276. [CrossRef]

10. Korpas, J.; Tomori, Z. Cough and Other Respiratory Reflexes; Karger: Basel, Switzerland, 1979. [CrossRef]

11. Cherniack, R.M.; Naimark, A.; Cherniack, L. Respiration in Health and Disease; WB Saunders: Philadelphia, PA, USA, 1972; p. 496.

12. Collier, J.G.; Fuller, R.W. Capsaicin inhalation in man and the effects of sodium cromoglycate. Br. J. Pharmacol. 1984, 81, 113-117. [CrossRef]

13. Bickerman, H.A.; Barach, A.L. The experimental production of cough in human subjects induced by citric acid aerosols; preliminary studies on the evaluation of antitussive agents. Am. J. Med. Sci. 1954, 228, $156-163$. [CrossRef] [PubMed]

14. Bickerman, H.A.; German, E.; Cohen, B.M.; Itkin, S.E. The cough response of healthy human subjects stimulated by citric acid aerosol. II. Evaluation of antitussive agents. Am. J. Med. Sci. 1957, 234, 191-206. [CrossRef] [PubMed]

15. LoMauro, A.; Aliverti, A. Respiratory muscle activation and action during voluntary cough in healthy humans. J. Electromyogr. Kinesiol. 2019, 49, 102359. [CrossRef] [PubMed]

16. Ward, K.; Rao, P.; Reilly, C.C.; Rafferty, G.F.; Polkey, M.I.; Kalra, L.; Moxham, J. Poor cough flow in acute stroke patients is associated with reduced functional residual capacity and low cough inspired volume. BMJ Open Respir. Res. 2017, 4, e000230. [CrossRef]

17. Smith, J.A.; Aliverti, A.; Quaranta, M.; McGuinness, K.; Kelsall, A.; Earis, J.; Calverley, P.M. Chest wall dynamics during voluntary and induced cough in healthy volunteers. J. Physiol. 2012, 590, 563-574. [CrossRef]

18. Kang, S.W.; Shin, J.C.; Park, C.I.; Moon, J.H.; Rha, D.W.; Cho, D.H. Relationship between inspiratory muscle strength and cough capacity in cervical spinal cord injured patients. Spinal Cord 2006, 44, 242-248. [CrossRef]

19. Bahat, G.; Tufan, A.; Ozkaya, H.; Tufan, F.; Akpinar, T.S.; Akin, S.; Bahat, Z.; Kaya, Z.; Kiyan, E.; Erten, N.; et al. Relation between hand grip strength, respiratory muscle strength and spirometric measures in male nursing home residents. Aging Male Off. J. Int. Soc. Study Aging Male 2014, 17, 136-140. [CrossRef]

20. Lavietes, M.H.; Smeltzer, S.C.; Cook, S.D.; Modak, R.M.; Smaldone, G.C. Airway dynamics, oesophageal pressure and cough. Eur. Respir. J. 1998, 11, 156-161. [CrossRef]

21. Singh, P.; Murty, G.E.; Mahajan, R.P.; Knights, D.; Aitkenhead, A.R. The tussometer: Accuracy and reproducibility. Br. J. Anaesth. 1994, 73, 145-148. [CrossRef] 
22. Freitas, F.S.; Ibiapina, C.C.; Alvim, C.G.; Britto, R.R.; Parreira, V.F. Relationship between cough strength and functional level in elderly. Rev. Bras. Fisioter. (Sao Carlos (Sao PauloBraz.)) 2010, 14, 470-476. [CrossRef]

23. Sancho, J.; Servera, E.; Diaz, J.; Marin, J. Predictors of ineffective cough during a chest infection in patients with stable amyotrophic lateral sclerosis. Am. J. Respir. Crit. Care Med. 2007, 175, 1266-1271. [CrossRef] [PubMed]

24. Sancho, J.; Servera, E.; Diaz, J.; Marin, J. Comparison of peak cough flows measured by pneumotachograph and a portable peak flow meter. Am. J. Phys. Med. Rehabil. 2004, 83, 608-612. [CrossRef] [PubMed]

25. Bai, L.; Duan, J. Use of Cough Peak Flow Measured by a Ventilator to Predict Re-Intubation When a Spirometer Is Unavailable. Respir. Care 2017, 62, 566-571. [CrossRef] [PubMed]

26. Kikuchi, K.; Satake, M.; Kimoto, Y.; Iwasawa, S.; Suzuki, R.; Kobayashi, M.; Wada, C.; Shioya, T. Approaches to Cough Peak Flow Measurement With Duchenne Muscular Dystrophy. Respir. Care 2018, 63, 1514-1519. [CrossRef] [PubMed]

27. Bach, J.R.; Saporito, L.R. Criteria for extubation and tracheostomy tube removal for patients with ventilatory failure. A different approach to weaning. Chest 1996, 110, 1566-1571. [CrossRef] [PubMed]

28. Mellies, U.; Goebel, C. Optimum insufflation capacity and peak cough flow in neuromuscular disorders. Ann. Am. Thorac. Soc. 2014, 11, 1560-1568. [CrossRef] [PubMed]

29. Silverman, E.P.; Carnaby-Mann, G.; Pitts, T.; Davenport, P.; Okun, M.S.; Sapienza, C. Concordance and discriminatory power of cough measurement devices for individuals with Parkinson disease. Chest 2014, 145, 1089-1096. [CrossRef]

30. Suarez, A.A.; Pessolano, F.A.; Monteiro, S.G.; Ferreyra, G.; Capria, M.E.; Mesa, L.; Dubrovsky, A.; De Vito, E.L. Peak flow and peak cough flow in the evaluation of expiratory muscle weakness and bulbar impairment in patients with neuromuscular disease. Am. J. Phys. Med. Rehabil. 2002, 81, 506-511. [CrossRef]

31. Tzani, P.; Chiesa, S.; Aiello, M.; Scarascia, A.; Catellani, C.; Elia, D.; Marangio, E.; Chetta, A. The value of cough peak flow in the assessment of cough efficacy in neuromuscular patients. A cross sectional study. Eur. J. Phys. Rehabil. Med. 2014, 50, 427-432. [PubMed]

32. Kimura, Y.; Takahashi, M.; Wada, F.; Hachisuka, K. Differences in the Peak Cough Flow among Stroke Patients With and Without Dysphagia. J. Uoeh 2013, 35, 9-16. [CrossRef] [PubMed]

33. Cesareo, A.; LoMauro, A.; Santi, M.; Biffi, E.; D’Angelo, M.G.; Aliverti, A. Acute Effects of Mechanical Insufflation-Exsufflation on the Breathing Pattern in Stable Subjects With Duchenne Muscular Dystrophy. Respir. Care 2018, 63, 955-965. [CrossRef] [PubMed]

34. Kulnik, S.T.; MacBean, V.; Birring, S.S.; Moxham, J.; Rafferty, G.F.; Kalra, L. Accuracy of portable devices in measuring peak cough flow. Physiol. Meas. 2015, 36, 243-257. [CrossRef] [PubMed]

35. Bach, J.R.; Ishikawa, Y.; Kim, H. Prevention of pulmonary morbidity for patients with Duchenne muscular dystrophy. Chest 1997, 112, 1024-1028. [CrossRef] [PubMed]

36. Matsuda, C.; Shimizu, T.; Nakayama, Y.; Haraguchi, M. Cough peak flow decline rate predicts survival in patients with amyotrophic lateral sclerosis. Muscle Nerve 2019, 59, 168-173. [CrossRef]

37. Beuret, P.; Roux, C.; Auclair, A.; Nourdine, K.; Kaaki, M.; Carton, M.J. Interest of an objective evaluation of cough during weaning from mechanical ventilation. Intensive. Care Med. 2009, 35, 1090-1093. [CrossRef]

38. Duan, J.; Zhou, L.; Xiao, M.; Liu, J.; Yang, X. Semiquantitative cough strength score for predicting reintubation after planned extubation. Am. J. Crit. Care Off. Publ. Am. Assoc. Crit. Care Nurses 2015, 24, e86-e90. [CrossRef]

39. Finder, J.D.; Birnkrant, D.; Carl, J.; Farber, H.J.; Gozal, D.; Iannaccone, S.T.; Kovesi, T.; Kravitz, R.M.; Panitch, H.; Schramm, C.; et al. Respiratory care of the patient with Duchenne muscular dystrophy: ATS consensus statement. Am. J. Respir. Crit. Care Med. 2004, 170, 456-465. [CrossRef]

40. Bach, J.R.; Bianchi, C.; Vidigal-Lopes, M.; Turi, S.; Felisari, G. Lung inflation by glossopharyngeal breathing and "air stacking" in Duchenne muscular dystrophy. Am. J. Phys. Med. Rehabil. 2007, 86, 295-300. [CrossRef]

41. Bach, J.R.; Martinez, D. Duchenne muscular dystrophy: Continuous noninvasive ventilatory support prolongs survival. Respir. Care 2011, 56, 744-750. [CrossRef]

42. Ishikawa, Y.; Miura, T.; Ishikawa, Y.; Aoyagi, T.; Ogata, H.; Hamada, S.; Minami, R. Duchenne muscular dystrophy: Survival by cardio-respiratory interventions. Neuromuscul. Disord. 2011, 21, 47-51. [CrossRef]

43. Bach, J.R.; Upadhyaya, N. Association of Need for Tracheotomy with Decreasing Mechanical In-Exsufflation Flows in Amyotrophic Lateral Sclerosis. Am. J. Phys. Med. Rehabil. 2018, 97, e20-e22. [CrossRef] [PubMed] 
44. Bach, J.R.; Giménez, G.C.; Chiou, M. Mechanical In-exsufflation-Expiratory Flows as Indication for Tracheostomy Tube Decannulation: Case Studies. Am. J. Phys. Med. Rehabil. 2019, 98, e18-e20. [CrossRef] [PubMed]

45. Omari, T.I.; Kritas, S.; Cock, C.; Besanko, L.; Burgstad, C.; Thompson, A.; Rommel, N.; Heddle, R.; Fraser, R.J.L. Swallowing dysfunction in healthy older people using pharyngeal pressure-flow analysis. Neurogastroenterol. Motil. 2014, 26, 59-68. [CrossRef] [PubMed]

46. Sakai, Y.; Ohira, M.; Yokokawa, Y. Cough Strength Is an Indicator of Aspiration Risk When Restarting Food Intake in Elderly Subjects with Community-Acquired Pneumonia. Respir. Care 2020, 65, 169-176. [CrossRef] [PubMed]

47. Huang, C.-T.; Yu, C.-J. Conventional Weaning Parameters Do Not Predict Extubation Outcome in Intubated Subjects Requiring Prolonged Mechanical Ventilation. Respir. Care 2013, 58, 1307-1314. [CrossRef]

48. Thille, A.W.; Boissier, F.; Ben Ghezala, H.; Razazi, K.; Mekontso-Dessap, A.; Brun-Buisson, C. Risk factors for and prediction by caregivers of extubation failure in ICU patients: A prospective study. Crit. Care Med. 2015, 43, 613-620. [CrossRef]

49. Birring, S.S.; Matos, S.; Patel, R.B.; Prudon, B.; Evans, D.H.; Pavord, I.D. Cough frequency, cough sensitivity and health status in patients with chronic cough. Respir. Med. 2006, 100, 1105-1109. [CrossRef]

50. Birring, S.S.; Fleming, T.; Matos, S.; Raj, A.A.; Evans, D.H.; Pavord, I.D. The Leicester Cough Monitor: Preliminary validation of an automated cough detection system in chronic cough. Eur. Respir. J. 2008, 31, 1013-1018. [CrossRef]

51. Spinou, A.; Birring, S.S. An update on measurement and monitoring of cough: What are the important study endpoints? J. Thorac. Dis. 2014, 6, S728-S734. [CrossRef]

52. Kraman, S.S. The relationship between airflow and lung sound amplitude in normal subjects. Chest 1984, 86, 225-229. [CrossRef]

53. Dosani, R.; Kraman, S.S. Lung sound intensity variability in normal men. A contour phonopneumographic study. Chest 1983, 83, 628-631. [CrossRef]

54. Shykoff, B.E.; Ploysongsang, Y.; Chang, H.K. Airflow and normal lung sounds. Am. Rev. Respir. Dis. 1988, 137, 872-876. [CrossRef]

55. Umayahara, Y.; Soh, Z.; Ozaki, T.; Murakami, T.; Otsuka, A.; Tsuji, T. Ability to cough can be evaluated through cough sounds: An experimental investigation of effects of microphone type on accuracy. In Proceedings of the 2017 IEEE/SICE International Symposium on System Integration (SII), Taipei, Taiwan, 11-14 December 2017; pp. 936-941.

56. Umayahara, Y.; Soh, Z.; Sekikawa, K.; Kawae, T.; Otsuka, A.; Tsuji, T. Estimation of Cough Peak Flow Using Cough Sounds. Sensors 2018, 18, 2381. [CrossRef]

57. Smith Hammond, C.A.; Goldstein, L.B.; Zajac, D.J.; Gray, L.; Davenport, P.W.; Bolser, D.C. Assessment of aspiration risk in stroke patients with quantification of voluntary cough. Neurology 2001, 56, 502-506. [CrossRef]

58. Umayahara, Y.; Soh, Z.; Sekikawa, K.; Kawae, T.; Otsuka, A.; Tsuji, T. A Mobile Cough Strength Evaluation Device Using Cough Sounds. Sensors 2018, 18, 3810. [CrossRef]

(C) 2020 by the authors. Licensee MDPI, Basel, Switzerland. This article is an open access article distributed under the terms and conditions of the Creative Commons Attribution (CC BY) license (http://creativecommons.org/licenses/by/4.0/). 